Examination of sputum provides a direct method to investigate airway inflammation non-invasively in particular Th 1 (IL-2, IFN- $\gamma$ ) and Th 2 (IL-4, IL-10) cytokine production.

IL-2, IL-4, IL-10 and IFN- $\gamma$ cytokine were studied in induced sputum mononuclear cells of asthmatic patien ts.

Sputum induction was performed on 10 patients and 10 normal controls. Basal and mitogen-stimulated cytokine production was determined in induced sputum T-cell culture. Supernatants were collected and assayed not only with specific ELISA but also with polymerase chain reaction (PCR) techniques.

Data showed a significantly higher production of IL-10 by both the ELISA and the RT-PCR techniques in asthmatic patients compared with sputum mononuclear cells from healthy controls. IL-4 production was detected at a low level using the ELISA method in asthmatic patients. The RT-PCR analysis detected a significantly IL-4-m RNA expression in all asth matic patients, compared with controls. Results of IL-10 and IL-4 mRNA expression were reproducible. We did not find any alteration in the expression of the type 1 derived cytokines (IL-2 and IFN- $\gamma$ ) in asthmatic patients or in healthy controls.

Our study showed a tendency of induced sputum mononuclear cells to express a Th2-like cytokine pattern in acute exacerbation of asthmatic patients, where IL-10 and IL-4 are synthesized in larger amounts. The combination of sputum induction as a non-invasive tool to explore the lung and the identification of disease-associated cytokine expression and of $s$ pecific cytokine mRNA should help elucidate mechanisms of the immunologically mediated inflammatory responses in asthma.

Key words: Asthma, Th1 and Th2, Inflammation

\section{Inflammatory response in induced sputum mononuclear cells from patients with acute exacerbation of asthma}

\author{
A. Hamzaoui ${ }^{1, C A}$, M. Ben Brahim², A. Zhioua ${ }^{3}$, \\ Kh. Ayed ${ }^{4}$ and K. Hamzaoui ${ }^{3}$
}

${ }^{1}$ A. Mami Hospital, Department of Pediatric Respiratory Diseases, Pavillon B, Ariana; ${ }^{2}$ Department of Physiology, Medicine University of Tunis, Pavillon 6; ${ }^{3}$ Immuno-Histology Laboratory, Medicine University of Tunis, Pavillon 6. Research Unit of the 'Ministère de I'Enseignement Supérieur et de la Recherche Scientifique', Code: 99/UR/08-40; ${ }^{4}$ Department of Immunopathology, Ch. Nicole Hospital.

${ }^{\mathrm{CA}}$ Corresponding Author
Fax: (216) 1569427
Email: Kamel.Hamzaoui@fmt.rnu.tn 
patients have a Th1-like pattern of cytokine production including IL- 2 and IFN-g but no IL- 4 or IL$5 .{ }^{10}$

Induced sputum provides a direct method to investigate airway inflammation non-invasively. When sputum cannot be produced spontaneously, it usually can be successfully induced by inhalation of an aerosol of hypertonic saline. Sputum cell counts can be reproducible, reliable and valid. New methods of examination using cytospins of dithiothreitol-treated sputum improve reliability and reduce the time of examination. ${ }^{11}$ The cells can also be stained immunohistochemically for activation markers and the cell supernatant can be used to investigate fluid phase constituents. The use of sputum allows us to study inflammatory mononuclear cells and programmed cell death in asthma. ${ }^{11,12}$ Its application to the study of Th1 and Th2 in asthma disease should improve understanding of the pathogenesis.

The present paper describes the role of induced sputum T-lymphocytes in the inflammatory response of different forms of asthma patients, focusing mainly on the analysis of the Th1 (IL-2 and IFN-g) and Th2 (IL-4 and IL-10) lymphocyte, using the ELISA method and mRNA analyses. The role of Th1 and Th2 cells in mediating the selective infiltration of inflammatory cells will be discussed.

\section{Patients and methods}

\section{Patients}

Induced sputum samples were collected from 10 successive patients with asthma. All were inpatients, admitted for an acute wheezing exacerbation of dyspnoea, usually as an emergency. The sample was obtained the day after admission. A precise history of the patient was subsequently obtained, and after recovery functional respiratory tests and eventually skin tests were carried out. Patients with the following diagnoses were excluded: concomitant infectious pneumonia, tuberculosis, interstitial lung diseases, bronchiectasis, lung cancer, and associated acute pathologies: cardiac, renal, liver, or neurological diseases. The induced sputum from 10 healthy subjects (mean age $28.7 \mathrm{yrs}$; range 22-36), who had normal pulmonary radiographs and showed no clinical signs of respiratory disease, acted as controls. Informed consent was obtained from all patients. The study was approved by the local Ethics Committee.

Serum IgE levels were elevated in most patients (range $110-940 \mathrm{U} / \mathrm{ml}$ ). In healthy controls the serum IgE levels were $<100 \mathrm{U} / \mathrm{ml}$.

\section{Sputum induction}

After the inhalation of salbutamol $(2 \times 200 \mathrm{mg})$, subjects were asked to inhale sterile, pyrogen-free, hypertonic saline in increasing concentrations for a duration of $10 \mathrm{~min}$. The hypertonic saline was nebulized via an ultrasonic nebulizer. Subjects were encouraged to cough throughout the procedure. Most patients were able to expectorate an adequate sample (7 $\mathrm{ml}$ and more) within the first $10 \mathrm{~min}$.

\section{Sputum processing}

In order to reduce salivary contamination, plugs were selected and transferred into an Eppendorf tube. A freshly prepared $10 \%$ solution of dithiothreitol (1 ml) (DTT) was added. The tube was vortex mixed and the sputum was incubated for $5 \mathrm{~min}$ at room temperature, filtered through $52 \mathrm{~mm}$ nylon gauze to remove debris and mucus, and subsequently centrifuged at $450 \times g$ for $10 \mathrm{~min}$. The cell pellet was resuspended in phosphate-buffered saline (PBS) in a volume equal to the sputum plus DTT solution volume. Total cell counting was carried out in a haemocytometer and the cell concentration was adjusted to $1.0 \times 10^{6} \mathrm{cells} / \mathrm{ml}$. Cytospins were prepared by adding $75 \mathrm{ml}$ cell suspension into Shandon II cytocentrifuge cups (Shandon Southern Instruments) and spun for $8 \mathrm{~min}$ at $500 \mathrm{rpm}$. Two slides were stained with Wright-Giemsa for an overall differential cell count of leukocytes, bronchial epithelial cells and squamous cells. Slides were coded and counted blind by two investigators. None of the cytospins contained $>5 \%$ squamous epithelial cells. For cell differentiation, 400 nucleated cells per slide were counted and expressed as a percentage of intact round nucleated cells, excluding the squamous epithelial cells.

\section{T-cell culture}

Lymphocytes were isolated by Ficoll-Hypaque (Pharmacia, Uppsala, Sweden) density gradient centrifugation and washed twice with PBS at $4{ }^{\circ} \mathrm{C}$, as we have recently reported. ${ }^{5}$ The cell pellet expressed more than $80 \%$ CD3-positive cells as determined by antiCD3 monoclonal antibody (Becton Dickinson).

T lymphocytes were diluted in RPMI 1640, and $1 \mathrm{ml}$ aliquots were deposited in $2 \mathrm{ml}$ wells of a 24-well plate (Falcon). Basal and mitogen stimulated [phytohaemagglutinin (PHA; Sigma, St Louis, M final concentration of $5 \mathrm{mg} / \mathrm{ml}$ ); and lipopolysaccharide (LPS, from Salmonella enteritidis; Sigma, final concentration $25 \mathrm{mg} / \mathrm{ml}$ )] conditions were evaluated. The plates were incubated at $37^{\circ} \mathrm{C}$ in a $\mathrm{CO}_{2}$ atmosphere. After culture periods of $24 \mathrm{~h}$ and $48 \mathrm{~h}$ the contents of the wells were harvested, spun at $2000 \times g$ for $2 \mathrm{~min}$ and the supernatants were collected and stored frozen at $-80^{\circ} \mathrm{C}$ until use. Sputum induced-cells were used for mRNA analysis. 


\section{Cytokine assays}

Culture supernatants were collected after $24 \mathrm{~h}$ to measure the IL -4 and IFN-g contents and after $48 \mathrm{~h}$ to evaluate IL-10.

Supernatant cytokine concentrations were determined by ELISA (Immunotech, Bio-Care, Tunis). The positivity thresholds were $10 \mathrm{pg} / \mathrm{ml}$ for IL-2, $0.08 \mathrm{U} / \mathrm{ml}$ for IFN $-\mathrm{g}, 1.5 \mathrm{pg} / \mathrm{ml}$ for IL- 4 and $3 \mathrm{pg} / \mathrm{ml}$ for IL-10 (Immunotech, Bio-Care, Tunis).

\section{RNA extraction}

After incubation for an appropriate time, cells were isolated by brief centrifugation and then stored in $1 \mathrm{ml}$ Trizol (Gibco, at $-80^{\circ} \mathrm{C}$ until further processing. RNA extraction was performed using phenol chloroform extraction and ethanol precipitation following the manufacturer's instructions. The RNA content of the solution was quantified using the optical density (OD) at $260 \mathrm{~nm}$ measured on a SECOMAN spectrophotometer and the RNA aliquots were stored at $-80^{\circ} \mathrm{C}$ until analysed. The ratio $260 / 280 \mathrm{~nm}$ was always more than $1: 8$.

\section{Reverse transcription and PCR}

cDNA was synthesized from oligo-dT-primed RNA by reverse transcription (RT) with $\mathrm{M}$-MLV superscript reverse transcriptase (Gibco). The total RNA mixture was incubated with $200 \mathrm{UM}-\mathrm{MLV}$ reverse transcriptase, $20 \mathrm{U}$ RNasin, $0.5 \mathrm{mM}$, dNTPs, $25 \mathrm{mg} / \mathrm{ml}$ primer dT, $10 \mathrm{mM}$ dithiothreitol, $50 \mathrm{mM}$ Tris-HCI pH 8.3, $75 \mathrm{mM} \mathrm{KCI}$ and $3 \mathrm{mM} \mathrm{MgCl}_{2}$, in a final volume of $20 \mathrm{ml}$ for $50 \mathrm{~min}$ at $42^{\circ} \mathrm{C}$. The final cDNA product was stored at $-20^{\circ} \mathrm{C}$ for subsequent cDNA amplification by PCR.

Reaction mixtures for PCR of $b$-actin and cytokines contained $2 \mathrm{ml}$ sample, $0.5 \mathrm{mM}$ dNTP, $0.5 \mathrm{U}$ Taq polymerase, $1 \mathrm{mg}$ of each primer, $50 \mathrm{mM}$ Tris-HCI, $3 \mathrm{mM} \mathrm{MgCI}_{2}, 75 \mathrm{mM} \mathrm{KCI} 0.01 \%$ gelatin in a final volume of $100 \mathrm{ml}$. PCR was performed on a thermal cycler (Personal cycler Biometra, Germany). Reaction times for $\mathrm{g}$-actin were $94^{\circ} \mathrm{C} 1 \mathrm{~min} .65^{\circ} \mathrm{C} 1 \mathrm{~min}$, and $72^{\circ} \mathrm{C} 1 \mathrm{~min}$ for 28 cycles, followed by $10 \mathrm{~min}$ extension at $72^{\circ} \mathrm{C}$. Reaction times for cytokine PCR were as follows: for IL-4 and IL-10, $94^{\circ} \mathrm{C} 1 \mathrm{~min}, 65^{\circ} \mathrm{C} 1 \mathrm{~min}$ and $72^{\circ} \mathrm{C} 1 \mathrm{~min}$; for IL- 2 and IFN-g, $94^{\circ} \mathrm{C} 1 \mathrm{~min}, 55^{\circ} \mathrm{C}$ $1 \mathrm{~min}$ and $72^{\circ} \mathrm{C} 1 \mathrm{~min}$ for $38-40$ cycles followed by 10 min extension at $72^{\circ} \mathrm{C}$ for all cytokines.

Primer sequences for the internal control, g-actin. were 59-TAC ATG GCT GGG GTG TTG AA-39 for the downstream primer. and 59-AAG AGA GGC ATC CTC ACC CT-39 for the upstream primer. Primer sequences for cytokines were as follow: for IL4, 59-CTT CCC CCT CTG TTC TTC CT-39 for the 59 primer, and 59TTC CTG TCG AGC CGT TTC AG-39 for the 39 primer; for IL-10, 59-ATG CCC CAA GCT GAG AAC CAA GAC CCA-39 for the 59 primer, and 59-TCT CAA GGG GCT GGG TCA GCT ATC CCA-39 for the 39 primer; for IL-2, 59-AAC TCC TGT CTT GCATTG CAC TA-39, for the 59 primer, and 59-TTG CTG ATT AAG TCC CTG GGTC-39 for the 3 primer; for IFN-g, 59AGT TAT ATC TTG GCT TTT CA-39 for the 59 primer, and 59-ACC GAA TAA TTA GTC AGC TT-39 for the 39 primer. The primer sequences were chosen in two different exons. These primer sequences were confirmed to specifically amplify the corresponding cytokine cDNA by Southern blot analysis using a fluorescein-labelled internal probe. cDNA products were visualized by gel electrophoresis in $20 \%$ agarose after ethidium bromide staining. A cDNA positive control, a negative control and a DNA ladder were run with all PCR reactions. Amplifications resulted in 200-400 bp product, as determined by electrophoresis on $2 \%$ TEA agarose gel containing bromide ethidium.

\section{Dot-blot analysis}

PCR products were denatured and vacuum dot blotted onto Hybond-N membrane (Amersham, France). Specific probes were 39-end labelled with fluorescein-11-dUTP using the ECL 39-oligolabelling reagents (RPN 2130; Amersham). The sequences of internal probes were as follows: for $b$-actin, 59CCA ACT GGG ACG ACA TGG AGA AAA - 39: for IL-2, 59GGC CAC AGA ACT GAA ACA TCT-39; for IL-4, 59-CTC GGT GCT CAG AGT CTT CTG CTC T-39; for IL-10, 59-CAG GTG AAG AAT GCC TTT AAT AAG CTC CAA CAGAAA GGC ATC TAC AAA GCC ATG AGT GAC TTT GAC ATC-39; for IFN-9, 59-ATT TGG CTC TGC ATT TTT CT GT -39.

Following hybridization to the dot blots and incubation with anti-fluorescein-horseradish peroxidase (HRP) conjugate, detection of the bound peroxidase was performed using hydrogen peroxide and luminol. The amount of each spot was determined by densitometry analysis. All of the cytokine PCR products were analysed comparatively to the amount of $b$-actin detected in the same mRNA sample. All samples were checked in the same test run for each cytokine analysed. Separate cycle course experiments confirmed linearity of amplification for $b$-actin and cytokine cDNA over 20-35 cycles and 30-45 cycles, respectively. For each PCR, linearity of amplification relative to cDNA dilutions was over $1 / 5-1 / 20$ for $\mathrm{IL}-4$ and IFN-g, 1/5-1/40 for IL-2, 1/5-1/80 for IL-10 and $g$-actin.

\section{Statistical analysis}

The distributions of cytokine concentrations are reported as their median values, first and third 
Table 1. IL-2, IFN-g, IL-4 and IL-10 cytokine production by sputum T-cells from asthmatic patients and healthy controls

\begin{tabular}{|c|c|c|c|c|}
\hline \multirow[t]{2}{*}{ Cytokine } & \multicolumn{2}{|c|}{ Healthy controls } & \multicolumn{2}{|c|}{ Asthmatic patients } \\
\hline & Basal & LPS+PHA & Basal & LPS+PHA \\
\hline $\mathrm{IL}-2$ & $\begin{array}{r}14.79 \\
(10.58-22.75)\end{array}$ & $\begin{array}{r}16.92 \\
(12.42-68.32)\end{array}$ & $\begin{array}{r}11.62 \\
(10.39-36.93)\end{array}$ & $\begin{array}{c}43.6^{*} \\
(12.43-125.30)\end{array}$ \\
\hline IFN-g & $\begin{array}{r}0.163 \\
(0.092-0.746)\end{array}$ & $\begin{array}{r}17.824 \\
(8.53-42.29)\end{array}$ & $\begin{array}{r}0.172 \\
(0.128-4.96)\end{array}$ & $\begin{array}{r}22.183 \\
(3.56-98.32)\end{array}$ \\
\hline IL-10 & $\begin{array}{c}22.7 \\
(2.36-75.46)\end{array}$ & $\begin{array}{c}1407 \\
(870-1913)\end{array}$ & $\begin{array}{r}64.3^{*} \\
(37.41-131.6)\end{array}$ & $\begin{array}{l}3058.6^{* *} \\
(214.7-6592)\end{array}$ \\
\hline $\mathrm{IL}-4$ & $\begin{array}{r}1.912 \\
(1.66-2.94)\end{array}$ & $\begin{array}{r}34.25 \\
(2.63-98.4)\end{array}$ & $\begin{array}{c}2.21 \\
(1.97-7.94)\end{array}$ & $\begin{array}{c}67.35^{*} \\
(32.6--110.9)\end{array}$ \\
\hline
\end{tabular}

Results are given as medians and ranges, and expressed in pg/10 6 sputum T-cells. Results for IFN-g are expressed in U/10 6 sputum T-cells. * Statistical significance comparing asthmatic patients versus healthy controls: $p<0.01$ is considered significant.

quartiles. Comparisons between two sample populations were made with the non-parametric MannWhitney U-test, with the level of significance set at 0.05 . Tests were performed with the statistical software STATISTICA. Correlations were determined by linear regression and Spearman's rank correlation.

\section{Results}

\section{Cytokine production}

\section{Th 1 cytokines}

In the absence of exogenous stimuli, the spontaneous production of IL- 2 was at normal values in asthmatic patients and healthy controls (Table 1 ). After $24 \mathrm{~h}$ in the presence of LPS + PHA, IL-2 levels were higher in supernatants from both populations, with asthma patients' IL-2 concentrations being significantly higher than those of healthy controls (Table 1).

As for IL-2, basal IFN-g production was comparable for both populations. LPS + PHA stimulation increased these concentrations, without differences between patients and healthy controls (Table 1).

\section{Th2 cytokines}

Basal IL-10 production was significantly higher in asthmatic patients than healthy controls. Significantly higher amounts of IL-10 were also detected in samples from asthmatic patients compared with controls under culture conditions (Table 1).

Spontaneous IL-4 production differed between asthmatic patients and healthy controls (Table 1), but significance was not notable. Mitogen-activated sputum T-cells from both populations generated enhanced IL-4 concentrations, and low statistical difference between groups was observed (Table 1). All asthmatic patients stimulated sputum T-cells produced high amounts of IL-4.

\section{Expression of cytokine mRNA in sputum} mononuclear cells from asthmatic patients and healthy controls

Because the spontaneous secretion of IL -4 cytokine in sputum mononuclear cells is very low by ELISA, we studied the expression of cytokine genes in sputum cells with a semi-quantitative PCR technique. Cytokine-specific cDNA were normalized to the intensity of the $b$-actin product as a standard marker.

Data revealed spontaneous IL-4 mRNA expression in all asthmatic patients, whereas normal donors in most cases did not show specific signals $(p<0.0001)$ (Fig. 3). Representative examples of autoradiographs showing signals from sputum cells of asthmatics and normal donors after PCR amplification and specific hybridization are shown in Fig. 1.

The technique of RT-PCR amplification used in this study remained semi-quantitative; IL-10 mRNA expression appeared to be significantly enhanced in asthmatic patients compared with healthy controls ( $p$ $<0$. 001) (Fig. 3).

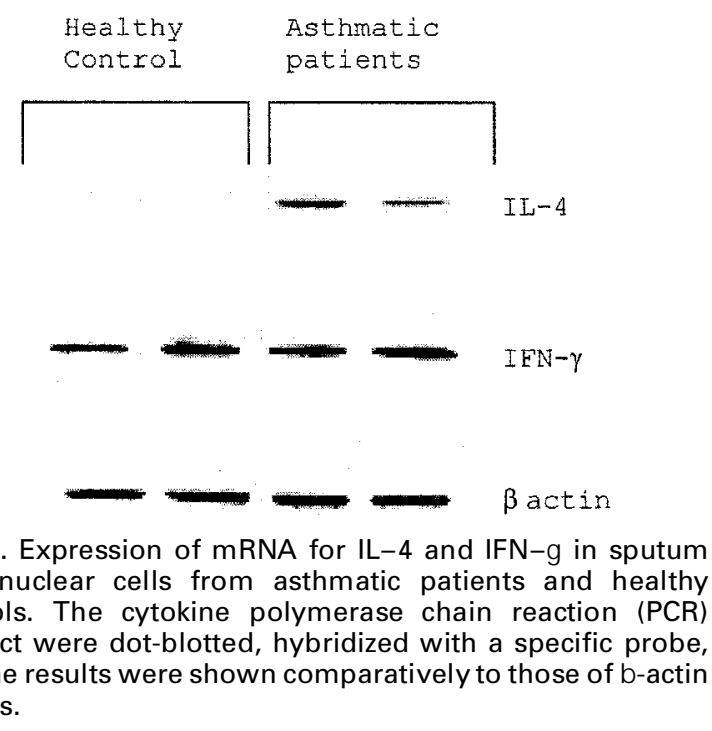



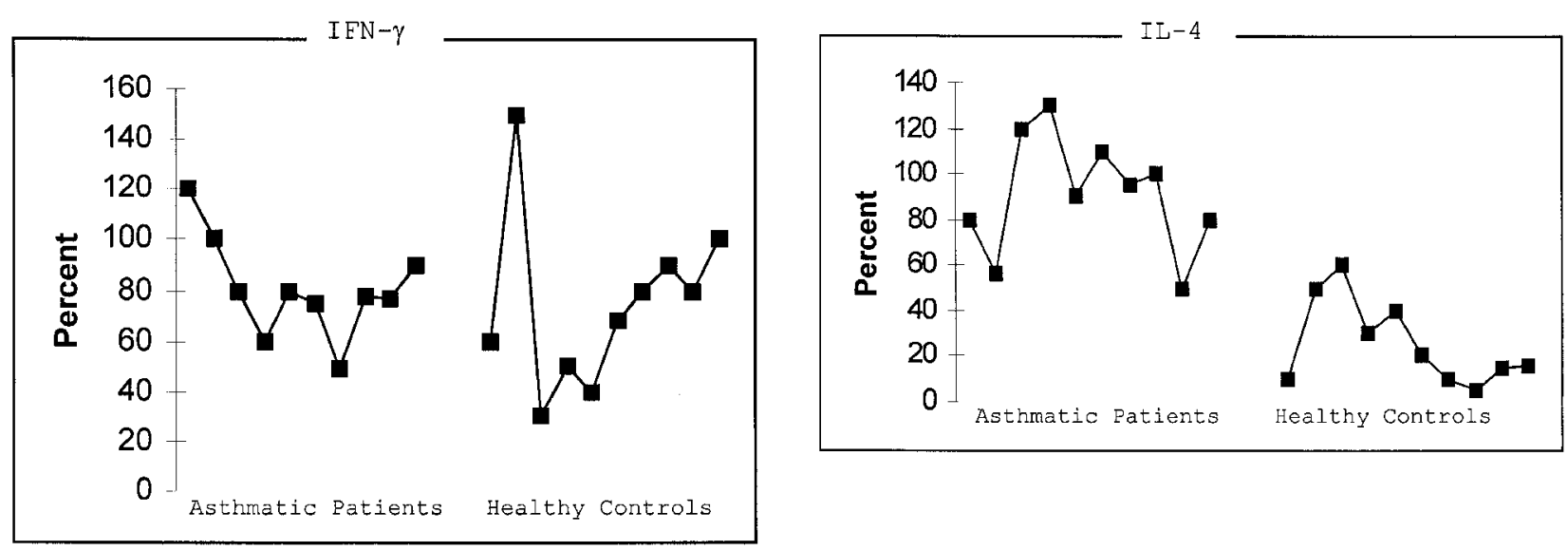

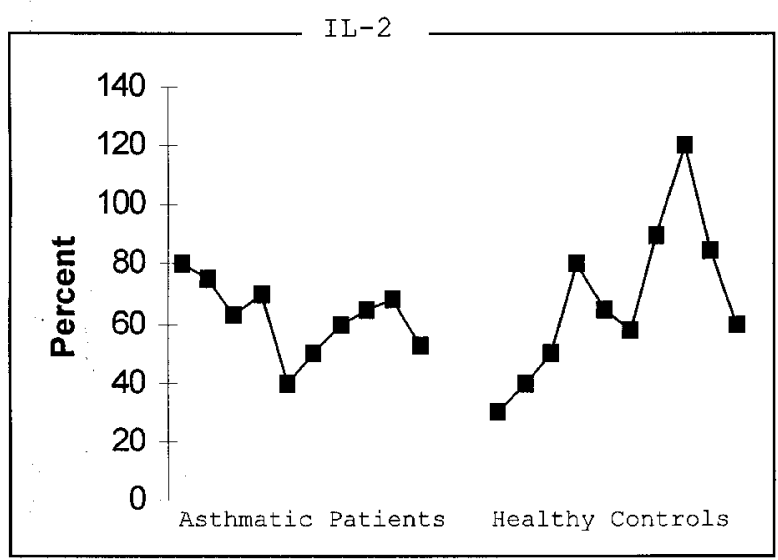

FIG. 2. Individual expression of mRNA for IFN-g and IL-2 in asthmatic patients and healthy controls in sputum mononuclear cells. The expression of mRNA is shown as percentages relative to the signals of $b$-actin.

Data shown in Fig. 2 indicate that the expression of mRNA for IFN-g and IL- 2 in asthmatic patients did not differ at all from healthy controls $(p=0.42$ and $p$ $=0.36$, respectively for IFN $-g$ and IL-2).

Using RT-PCR techniques, our results show a clear enhancement of spontaneous IL-10 mRNA expression in asthmatic patients over healthy controls. In addition, mRNA expression of the Th1 type derived cytokines (IL-2 and IFN-g) in the same experimental conditions did not differ between sputum induction cells of healthy controls and asthmatic patients.

\section{Correlations}

There is no correlation between the amount of IL4 mRNA expression, IL-10 mRNA expression, IFN$g$ mRNA expression and serum IgE levels. An inverse correlation is observed between IL-2 mRNA expression and serum IgE levels $(r=-0.72, p=$ $0.007)$.

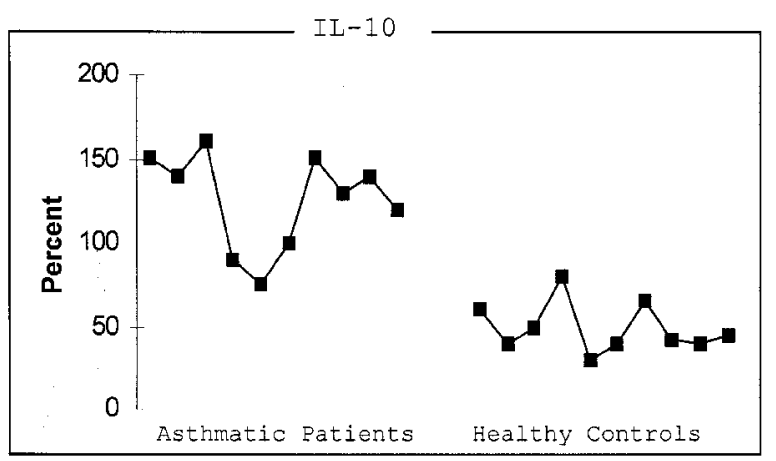

FIG. 3. Individual expression of mRNA for IL-4 and IL-10 in asthmatic patients and healthy controls in sputum mononuclear cells. The expression of mRNA is shown as percentages relative to the signals of $b$-actin.

A significant correlation between IL- 2 and IFN- $g$ production was established only when patients' $\mathrm{T}$ lymphocytes were stimulated $(r=0.57, p=0.0003)$.

\section{Discussion}

Thelper lymphocytes type 2 (Th2) are considered to play an essential role in orchestrating the inflammatory response associated with asthma. Th2 lymphocytes express cytokine-associated cell differentiation, eosinophil differentiation, mucus secretion, airway smooth muscle hyperreactivity, and mast cell hyperplasia. The aim of the present study was to determine the cytokine pattern during acute exacerbation of asthma, using the non-invasive method of induced sputum combined with the polymerase chain reaction. Our study focused on the cytokine production in culture supernatant sputum-T cells, of IL-2, IFN-g, IL- 10 and IL- 4 .

Total cell count was elevated in patients with asthma compared with healthy controls, as we have recently reported. ${ }^{12}$ Sputum cells of patients with asthma expressed high percentages of eosinophils and lymphocytes. The lymphocytes were in the majority CD3-positive (T lymphocytes). The leukocyte count and phenotype of the lymphocytes showed 
that sputum traduced an inflammatory state in patients with asthma. Our results obtained from analysing induced sputum in asthma patients reflect the inflammatory status of the bronchi. ${ }^{12}$

Th2 T-lymphocytes, characterized by the ability to produce cytokines such as IL- 4 and IL-10, have been largely implicated in the pathogenesis of allergic inflammation. In support of these results, studies on sputum cells from asthmatic individuals show high levels of IL- 4 and IL-10 in culture supernatants of mononuclear cells. These results were corroborated with the expression of mRNA expression of Th2associated cytokines IL- 4 and IL-10. Interleukin-10 secretion by monocytes and lymphocytes was responsible for the heightened immunoglobulin production. ${ }^{13}$ IL-10 production was also found to be enhanced in disorders characterized by prominent $\mathrm{B}$ lymphocyte hyperactivity, which results in increased production of immunoglobulin. ${ }^{14}$ IL-10 was originally characterized as a factor generated by Th 2 cells that inhibits cytokine synthesis by Thl cells. ${ }^{15}$ However, several other cell types have been further identified as a source of IL-10, including $\mathrm{CD}^{+}$and $\mathrm{CD}^{+}$T-lymphocytes, natural killer (NK) cells, monocytes/macrophages, B cells, mast cells, eosinophils, and bronchial epithelial cells. ${ }^{16}$ The concept that IL10 acts as an anti-inflammatory molecule emerged from its capacity to down-regulate the synthesis of a broad spectrum of proinflammatory cytokines produced by monocytes/macrophages and neutrophils. ${ }^{17}$

The immunosuppressive properties of IL-10 are mainly related to inhibition of antigen-presenting cell (APC) functions. Indeed, IL-10 downregulates the expression of class II major histocompatibility complex (MHC) and costimulatory molecules (e.g. intercellular adhesion molecule-1 (ICAM-1) on the membrane of monocytes/macrophages and inhibits their synthesis of inflammatory cytokines (IL-1, IL-6, IL-8 and tumour necrosis factor-a (TNF-a). The latter effect was also documented on alveolar macrophages. ${ }^{18}$ The inhibition of the local synthesis of TNFa secretion and the down-regulation of pulmonary vascular ICAM-I expression were shown to be involved in the protective effects of IL-10 against immunoglobulin $\mathrm{G}(\mathrm{IgG})$ immune complex-induced lung injury.

The increased expression of IL- 4 mRNA in asthmatic-induced sputum cells that we observed is consistent with the findings obtained by Brown et $a l .{ }^{19}$ in peripheral blood cells. Cytokine requirement for primary generation of the Th2 response in the lung was dependent on IL- $4 .{ }^{20}$ The ELISA method that we used displayed only $2.21 \mathrm{pg} / \mathrm{ml}$ in culture supernatant sputum mononuclear cells; one could suggest that sputum mononuclear cells needed more days stimulation and the sensitivity of the method remained insufficient for the detection of cytokine production.
The lack of spontaneous IL- 4 secretion reported by other authors ${ }^{19}$ in peripheral circulation indicated that this method is not representative of an inflammatory process localised in the lung. Cells obtained by induced sputum were more representative of the in situ inflammation in asthmatic patients, and use of the mRNA-PCR method was important. Our study ruled out the possibility of a lack of correlation between gene transcription and active synthesis of the relevant protein, since the increased spontaneous mRNA expression for IL- 4 as detected by PCR is compatible with the secretion of this cytokine.

IFN-g protein in sputum culture supernatant cells from asthmatic patients was comparable to healthy controls, after mitogenic stimulation. This result was consistent with other data. ${ }^{21}$

Our results demonstrated a tendency of $\mathrm{T}$ cells from a group of asthmatic patients to express a Th2 pattern with a high level of expression of IL- 4 and IL-10 cytokines. However, the classified Th2 cytokines reported in this paper can also be produced by Th 1 cells such as IL-10. ${ }^{22}$ The study of IL- 4 and IL-10 production in T cells from induced sputum could be the description of localised inflammatory process. A similar study should be corroborated with local B cell-IgE production. Such investigation should give information about the local $\mathrm{T}$ and $\mathrm{B}$ cell interaction.

Given that IgE production is considered to involve the production of Th2 cytokines, we were surprised at the lack of correlation of IL- 4 mRNA, IL- 10 mRNA and serum IgE levels. Other groups have shown that high and low IgE responders are under the control of IL- 4 expression, and that IL- 4 production correlates with serum IgE. ${ }^{23,24}$ The lack of correlation between serum IgE level and IL-10 mRNA expression could be explained by the fact that IL-10 induces B cell proliferation and production of isotypes IgM, IgG and IgA, with no effect on IgE synthesis. ${ }^{25}$ In these conditions, the IL-10/IL-2 and IL-10/IFN-g were examined (data not given). Enhanced ratios attributable to high IL-10 production were found for all asthmatic patients, and might trigger the $\mathrm{B}$ lymphocyte hyperactivity. Low ratios reflecting elevated IL10 and IL- 2 or IFN-g levels could be taken as marker of inflammation and tissue injury. Such interpretation could help us to understand the modulation of Th1 and Th2 cytokines.

Matzinger ${ }^{26}$ proposed the hypothesis that antigenic stimuli presented to a mucosal barrier interface direct the immune response towards the Th 2 phenotype and that the normal response is effectively to inhibit these processes through a variety of pathways, including tolerance, anergy and apoptosis. Th2 cytokine profiles were significantly more resistant to activation-induced apoptosis and bcl-2 expression was reported to be higher in Th2 cells than in those producing Th1 cytokines. ${ }^{24}$ Our recent results concerning apoptosis 
in acute exacerbation of asthma showed an increased bcl-2 expression in induced sputum mononuclear cells and the percentage of apoptosis was decreased. ${ }^{12}$ Resistance to activation-induced apoptosis may explain the expansion of cells producing Th2 cytokines. ${ }^{27}$

Our results provided indirect evidence in vivo for increased mRNA expression for IL- 4 and IL-10. The Th 1 and Th 2 cytokine profile may be significant in the analysis of clinical allergic responses in asthmatic patients. An improved understanding of the cellular and molecular mechanisms resulting in Th2 responses has suggested potential therapeutic strategies to inhibit Th2 responses associated with asthma. Further studies will need to determine whether alternative approaches to inhibit Th2 cells are practical in human subjects. The Th2-induced sputum cell appears to be a useful, non-invasive tool to explore the inflammation of asthma.

ACKNOWLEDGEMENTS. This work was financially supported by a grant from Chiesi Laboratory. We wish to thank $\mathrm{Mr} \mathrm{A}$. Boujarra for his technical assistance. We wish to thank Prof A. Kahan, INSERM U 283 for constructive discussion.

\section{References}

1. Lassale P, Sergant M, Delneste Y, Gosset P, Wallaert B, Zandeck M, Capron A, Joseph M, Tonnel AB. Levels of soluble IL-2 receptor in plasma from asthmatics. Correlations with blood eosinophilia, lung function, and corticisteroid therapy. Clin Exp Im munol 1992: 87:266-71

2. Corrigan CJ, Kay AB. T-cells and eosinophils in the pathogenesis of asthma. Im mu nology Today 1992: 13:501-7

3. Heusser CH, Brinkmann V, DelesspessE G. Kilshherr E. Blaser K, LE GrosK. Current concepts of IgE regulation. Allergy Clin Im munol News 1991: 3:47

4. Kidney JC, Wong AG, Efthimiadis A, Morris MM, Sears MR, Dolovich J, Hargreave FE. Elevated B cells in sputum of asthmatics. Close correlation with eosinophils. Am J Respir Crit Care Med 1996: 153:540-4

5. Miyajima A, Miyatkae S, Schreurs J. DE Vries J, Arai N, Yokota T, Arai K. Coordinate regulation of immune and inflammatory responses by T-cell derived Iymphokines. FASEB J 1988: 2:2462-73

6. Owen WF. Cytokine regulation of eosinophil inflammatory disease. Allergy Clin Im munol News 1991: 3:85-9

7. Romagnani S. Del Preta GF, Maggi E, Ricci M. Th1 andTh2 cells and their role in disease. Allergy Clin Im m unol News 1993: 5:19-22

8. Silberstein DS, David JR. The regulation of human eosinophil function by cytokines. Im mu nology Today 1987: 8:380-5

9. Street NE, Mosmann TR. Functional diversity of T-lymphocytes due to secretion of different cytokine patterns. FASEB J 1991: 5:171-7
10. Wierenga EA, Snoek M, DE Groot C, Cretien I, Bos JD, Jansen HM, Kapsenberg ML. Evidence for compartmentalisation of functional subsets of $\mathrm{CD}^{+}$T-lymphocytes in atopic patients. J Im munol 1990: 144:4651-6

11. Vignola AM, Chanez P, Siena L, Merendino A, Reina C, Gagliardo R, Profita M, Bousquet J, Bonsignori G. Evaluation of apoptosis of eosinophils, macrophages and $\mathrm{T}$ lymphocytes in mucosal biopsy specimens of patients with asthma and chronic bronchitis. J Allergy Clin Immunol 1999: 103:555-8

12. Hamzaoui A, Hamzaoui K, Salah H, Chabbou A. Lymphocyte apoptosis in patients with acute exacerbation of asthma. Mediators of Inflam mation 1999: 8:241-7

13. Llorente L, Zou W, Levy Y. Role of interleukin-10 in the B lymphocyte hyperactivity and autoantibody production of human systemic lupus erythematosus. J Exp Med 1995: 181:839-44

14. Llorente L, Richaud-Patin Y, Fior R, Alcocer-Varela J, Wijdenes J, Morel Fournier B, Galanaud P, Emilie D. In vivo production of interleukin-10 by non T cells in rheumatoid arthritis, Sjögren's syndrome, and systemic lupus erythematosus. Arthritis Rheum 1994: 37:1647-55

15. Fiorentino DF, Bond MW, MosmannTR. Two types of mouse T helper cell, IV: Th 2 clones secrete a factor that inhibits cytokine production by Th1 clones. J Exp Med 1989: 170:2081-95

16. Moore KW, Ogarra A, Malefyt RD, Vieira P, Mosmann TR. Interleukin-10. Annu Rev Immunol 1993: 11:165-90.

17. Cassatella MA, Meda L, Bonora S, Ceska M, Constantin. IL-10 inhibits the release of proinflammatory cytokines from human polymorphonuclear leukocytes: evidence for an autocrine role of tumor necrosis factor and $\mathrm{IL}-1$ beta in mediating the production of $\mathrm{IL}-8$ triggered by lipopolysaccharide. J Exp Med 1993: 78:2207-11

18. Thomassen MJ, Divis LT, Fisher CJ. Regulation of human alveolar macrophage inflammatory cytokine production by interleukin-10. Clin Im munol Im munopathol 1996: 80:321-4

19. Brown MA, Li SH, Chan SC. Interleukin -4 mRNA expression by normal and atopic T lymphocytes. Clin Res 1989: 37:406-12

20. Herrick CA, MacLeod H, Glusac E, Tigelaar RE, Bottomly K. Th2 responses induced by epicutaneous or inhalation protein exposure are differentially dependent on IL-4. J Clin Invest 2000: 105:765-75

21. Robinson DS, Qutyba H, Ying S. Predominant Th2 like bronchoalveolar T-lymphocyte population in atopic asthma. $N$ Engl J Med 1992: 326:298-304

22. DelPrete G, DeCarli M, Almengogna F. Human IL-10 is produced by both type I helperTh-1: and type 2 helper Th2: T cell clones and inhibits their antigen-specific proliferation and cytokine production. J Im mu nol 1993: 150:353-60

23. Pene J, Rivier A, Lagier B. Differences in IL- 4 release by PBMC are related to heterogeneity of atopy. Im m unology 1994: 81:58-64

24. Tang MLK, Coleman J, Kemp AS. Interleukin-4 and interferon-gamma production in atopic and non-atopic children with asthma. Clin Exp Allergy 1995: 25:515-21

25. Rousset F, Garcia E, DeFrance T. Interleukin-10 is a potent growth and differentiation factor for activated human B lymphocytes. Proc Natl Acad Sci USA 1992: 89:1890-5

26. Matzinger B. Tolerance, danger and the extended family. Ann Rev Im munol 1994: 12:991-1045

27. Carbonari M, Tedesco T, Delporto P, Paganelli R, Fiorilli M. Human T cells with a type- 2 cytokine profile are resistant to apoptosis induced by primary activation: consequences for immunopathogenesis. Clin Exp Im munol 2000: 120:454-62

Received 14 July 2000; accepted 28 July 2000 


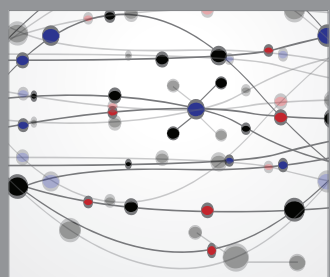

The Scientific World Journal
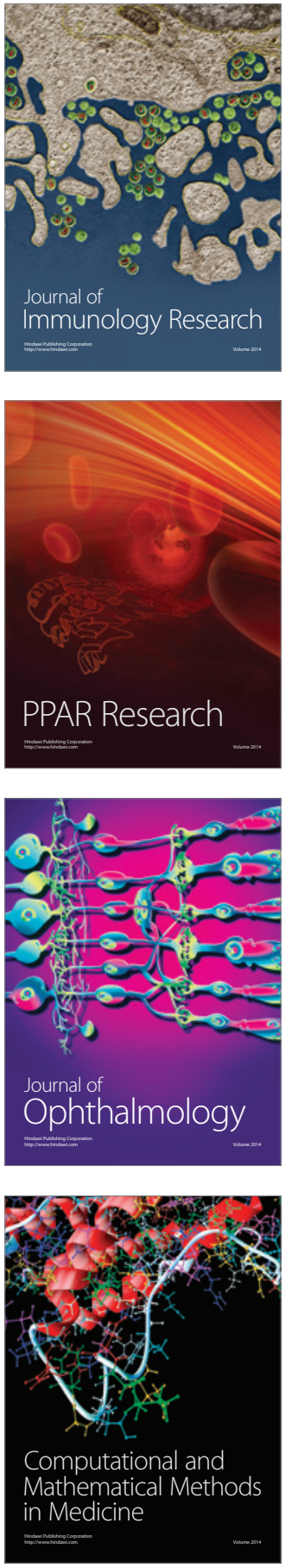

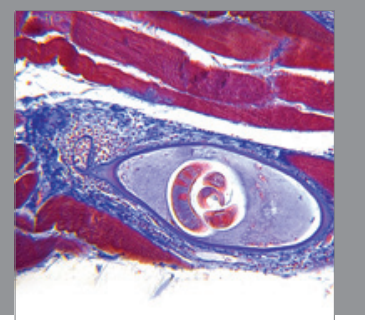

Gastroenterology

Research and Practice
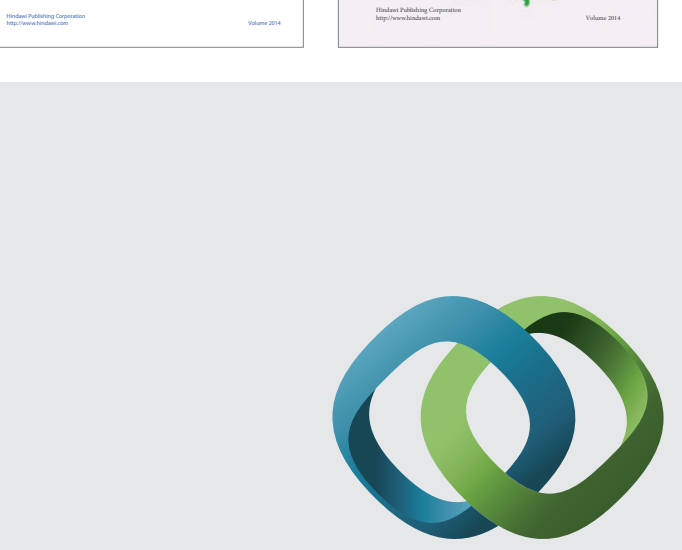

\section{Hindawi}

Submit your manuscripts at

http://www.hindawi.com
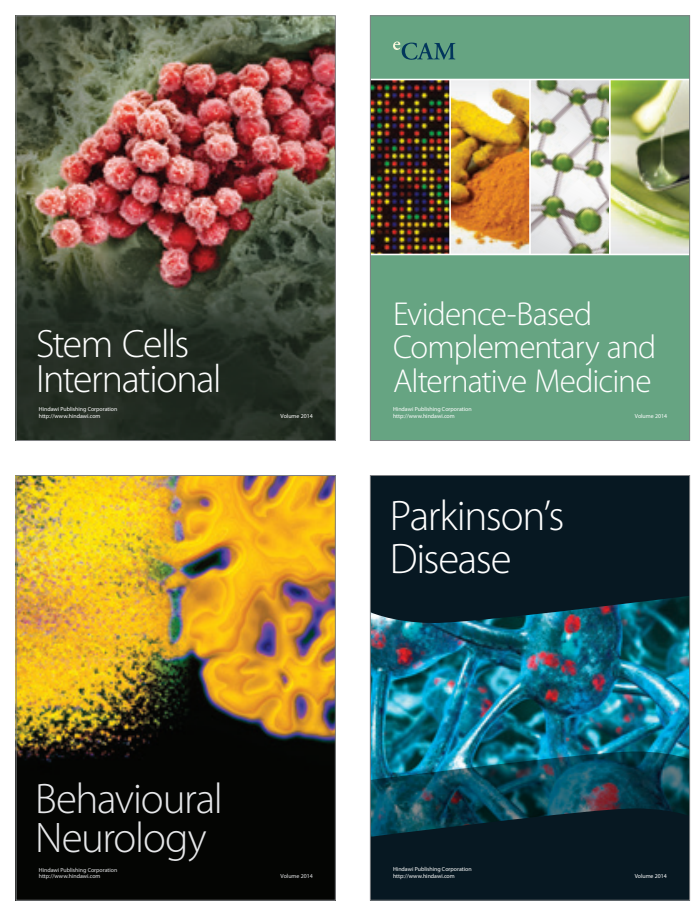

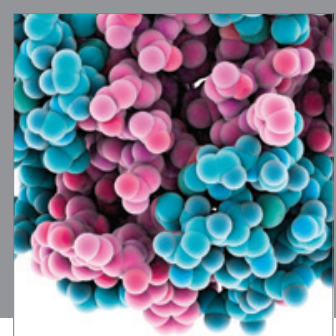

Journal of
Diabetes Research

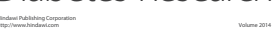

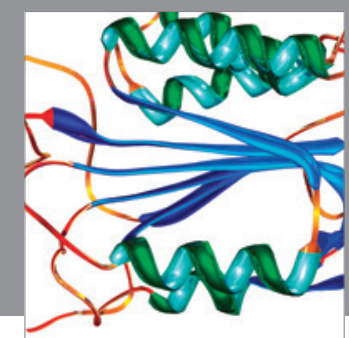

Disease Markers
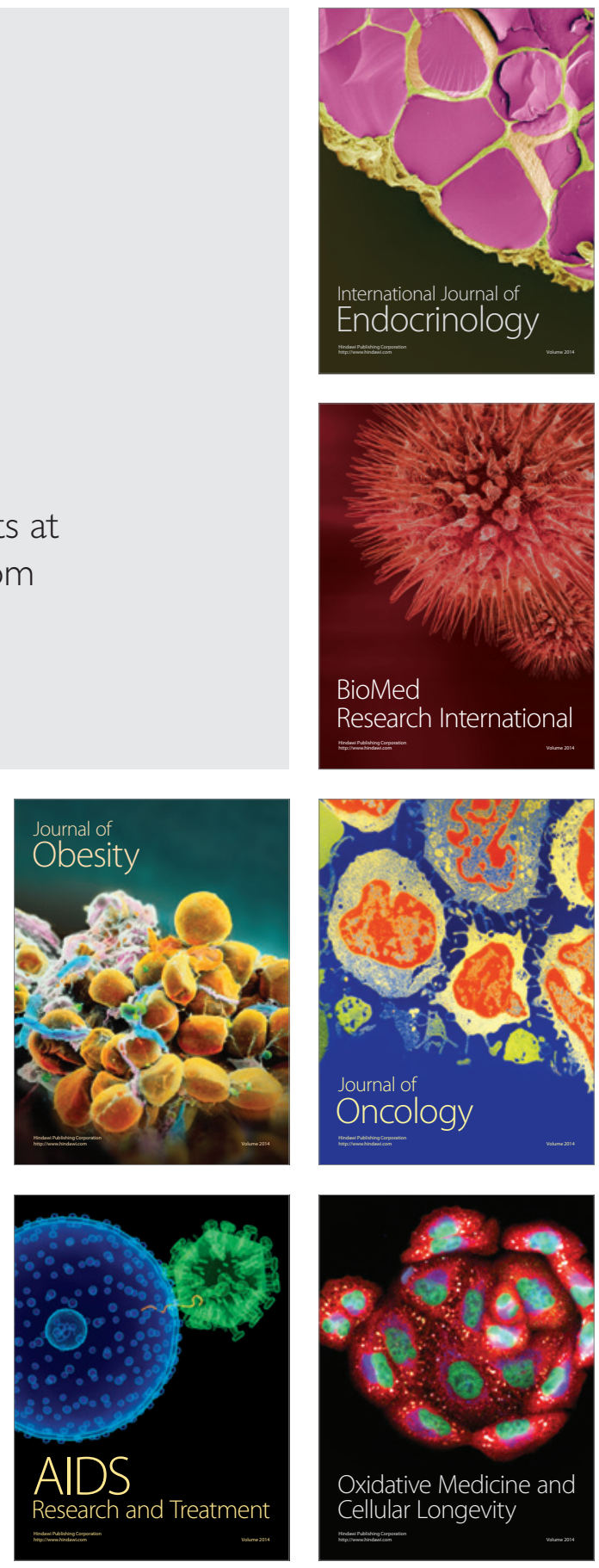